PARA ALÉM DA FRONTEIRA NACIONAL: A NECESSIDADE DE MECANISMOS PARA ABRANDAMENTO DOS REFLEXOS INTERNACIONAIS DAS VIOLAÇÕES

\title{
DE DIREITOS HUMANOS
}

\author{
Ana Cláudia Corrêa Zuin Mattos do Amaral ${ }^{1}$ \\ Rodrigo Ichikawa Claro Silva ${ }^{2}$
}

\begin{abstract}
RESUMO: Consiste em reflexões sobre o imperativo enquadramento universal das condutas estatais quando, não obstante a soberania, compõem uma ordem internacional esteada na integral tutela humana. Mais especificamente, atém-se às intervenções dos organismos internacionais, sobretudo no Sistema Interamericano, e ao crescente fenômeno do refúgio. Objetiva examinar a remediação das consequências internacionais da violação de direitos humanos. Utilizando o método dedutivo, com pesquisa bibliográfica, tem-se a conclusão de que, apesar da ampla gama de instrumentos formais, ainda há intensas afrontas aos direitos humanos, o que fomenta a necessidade pelo desenvolvimento de mecanismos hábeis à formação de uma sociedade global mais efetivamente humanizada.
\end{abstract}

Palavras-chave: Dignidade; Direitos Humanos; Responsabilidade Internacional; Refugiados; Sistema Interamericano;

\section{FOR BEYOND NATIONAL BORDER: THE NEED FOR MECHANISMS TO DECREASE THE INTERNATIONAL EFFECTS OF HUMAN RIGHTS VIOLATION}

\begin{abstract}
Consists with reflections on the imperative universal framework of states conducts when, despite sovereignty, constitute an international order based on integral human protection. More specifically, focuses on interventions by international organizations, especially in the Inter-American System, and the growing phenomenon of refuge. It aims to examine remediations of the international consequences of the violation to human rights. Using deductive method, with bibliographical research, it is concluded that, despite the wide range of formal instruments, there are still intense human rights abuses, which fosters the need for the development of mechanisms that are capable to form a more effectively humanized society.
\end{abstract}

Keywords: Dignity; Human Rights; International Responsibility; Refugees; Inter-American System.

\footnotetext{
${ }^{1}$ Doutora em Direito das Relações Sociais pela PUC-SP. Mestre em Direito Negocial pela Universidade Estadual de Londrina. Professora do Programa de Mestrado em Direito Negocial e do Curso de Graduação em Direito da Universidade Estadual de Londrina. Endereço Postal na Rodovia Celso Garcia Cid - Pr 445 Km 380 Cx. Postal 10.011 - Campus Universitário, PR, 86057-970CEP 87.015-230. E-mail: anaclaudiazuin@live.com ${ }^{2}$ Mestrando em Direito Negocial pela Universidade Estadual de Londrina. Mestre (bolsista CAPES) em Ciências Jurídicas pelo Centro Universitário de Maringá. Pós-Graduado em Direito Notarial e Registral pela LFGAnhanguera. Pós-Graduado em Direito Civil e Empresarial pelo Damásio Educacional. Graduado em Direito pela Universidade Estadual de Maringá. Endereço Postal na Rodovia Celso Garcia Cid - Pr 445 Km 380 Cx. Postal 10.011 - Campus Universitário, PR, 86057-970CEP 87.015-230. E-mail: r.rodrigosilva01 @ gmail.com
} 


\section{INTRODUÇÃO}

Constando a contemplação de parâmetros mínimos de proteção da pessoa indelevelmente no cerne do ordenamento global, cabe a todos Estados o dever de fazer compatibilizar suas ações e normativas para com a integral tutela e fomento do supremo valor da dignidade humana. Além do mais, o prisma de tutela dos direitos humanos não se afigura apenas localmente, mas sobremodo numa escala global que inclui a atuação dos organismos internacionais de controle.

Nada obstante, apesar de toda pessoa, por sua própria essência, ser destinatária de um amplo arcabouço protetivo, é manifesta a necessidade pela viabilização de meios e ações aptos à concretude da efetiva realização prática da salvaguarda delineada. Isto porque ainda se identificam, em diversas ordens, discrepâncias entre o sedimentado dever de busca por satisfatórios patamares de desenvolvimento e a efetiva realização prática dos direitos humanos, pois em determinados locais ainda persiste o acobertamento de violações, a impunidade de agentes e outras ações que objetam o mandamento internacional de tutela da dignidade humana.

Neste deslinde, frente a unidade que há de fundar toda ordem internacional, fica evidente que determinadas ideologias ou instabilidades econômicas, políticas, culturais, diplomáticas, jurídicas e sociais que acabam por ensejar graves violações aos direitos humanos, hão de preocupar todas as nações porque, além das consequências já refletidas a variados países, se tais conjunturas não forem remediadas poderão resultar na consolidação de desumanas situações, graves e irreversíveis o bastante para afetar toda a globalidade da social formação humana.

O trabalho direciona-se, portanto, a analisar determinadas consequências advindas de cenários de violação aos direitos humanos, notadamente quanto aos impactos refletidos no âmbito do quadro internacional de proteção integral, mais especificamente sobre o campo de atuação do denominado Sistema Interamericana de Direitos Humanos, bem como a extensão das responsabilidades atinentes aos maciços deslocamentos hodiernos de refugiados.

É justificada tal diligência em razão das atuais proporções representadas pelo enorme número de pessoas forçadamente deslocadas ou então desnudadas da mais básica tutela que lhes caberia. Tal problemática revela, nesta feita, uma profunda e quase sempiterna crise humanitária de projeção universal, notadamente porquanto incita a necessidade por um maior fomento de condições que assegurem o melhor desenvolvimento do ser humano e a 
(re)construção de uma sociedade mais digna, justa, legítima, solidária e efetivamente pautada sobre os firmamentos da efetividade dos direitos humanos.

Mormente, pretende-se implementar maior conscientização sobre a relevância de instrumentos, concretos e efetivos, debeladores dos presentes obstáculos à concretização dos direitos humanos, ao fim de notabilizar-se o papel e importância da cooperação internacional no tratamento das circunstâncias afrontadoras do arcabouço protetivo, no propósito da formação de um mundo que, voluntariamente, seja mais respeitoso a seu cumprimento.

Para desenvolvimento do texto, nos termos propostos, utilizou-se o método dedutivo através da interpretação sistemática de textos doutrinários e normativas pertinentes, seja de direito interno ou internacional, ao fim da realização dos objetivos traçados, na via da ordenação de específicas conclusões emanadas das percepções gerais que compõem o estudo.

\section{DIGNIDADE E DIREITOS HUMANOS}

Sem desestimar demais conceitos e referências sobre a pessoa3, pauta-se aqui por transcender pontuais divergências entre definições e entendimentos diversos, principalmente por não haver unicidade ou, sequer, melhor definição atribuída a determinados conceitos (em especial ao que tange à dignidade humana), para assim elencar-se a identificação de pontos comuns que, em essência, representam os atributos mais irredutivelmente humanos e, nesta configuração, impõem o devido respeito e tutela, sob qualquer circunstância, à dignidade humana. Na sede de um instruidor compêndio conceitual pode-se elencar que:

\footnotetext{
Assim sendo, tem-se por dignidade da pessoa humana a qualidade intrínseca e distintiva reconhecida em cada ser humano que o faz merecedor do mesmo respeito e consideração por parte do Estado e da comunidade, implicando, neste sentido, um complexo de direitos e deveres fundamentais que assegurem a pessoa tanto contra todo e qualquer ato de cunho degradante e desumano, como venham a lhe garantir as condições existenciais mínimas para uma vida saudável, além de propiciar e promover sua participação ativa e corresponsável nos destinos da própria existência e da vida em comunhão com os demais seres humanos (SARLET, 2013, p. 37).
}

Seguramente, ademais, a guarida da dignidade humana constitui ainda a pedra angular da própria manutenção do Estado, porquanto substancializa pluridimensionais esforços

\footnotetext{
${ }^{3}$ Em complemento Alain Supiot (2007, p. 33-34) elenca que: “O indivíduo, o sujeito, a pessoa, esses três pilares da constituição ocidental do ser humano têm em com um uma profunda ambivalência. O indivíduo é ao mesmo tempo o único e o semelhante; o sujeito é ao mesmo tempo o soberano e o sujeitado; a pessoa é ao mesmo tempo carne e espírito".
} 
protetivos aos bens jurídicos mais essenciais à pessoa, base de qualquer estrutura e instituição social. No mesmo deslinde, tem-se que o Direito também repousa seus principais fundamentos sobre a tutela dos substratos cruciais à integridade humana (HABERLE, 2013).

Para mais, ante a consideração de que a soberania e a interdependência simultaneamente cobrem os Estados, cujos interesses, problemas e relações cada vez mais ultrapassam seus próprios territórios, resta instituído um global quadro assegurador de valores mínimos, o qual por todos deve ser observado. Conceito este eclodido principalmente com o pós-Segunda Guerra Mundial ao assinalo da necessidade por uma maior cooperação internacional na busca pela universal tutela efetiva da dignidade humana (VERAS; SENHORAS, 2018, p. 65). Interessante neste ponto o seguinte ensinamento:

A recta ratio tem, com efeito, ao longo dos séculos sempre propugnado por um direito das gentes verdadeiramente universal. Definitivamente, não se pode visualizar a humanidade como sujeito do Direito a partir da ótica do Estado; o que se impõe é reconhecer os limites do Estado a partir da ótica da humanidade (TRINDADE, 2006, p. 28-29).

Nesta diretriz o arcabouço convencional composto por instrumentos internacionais de proteção dos direitos humanos veio a, universalmente, constituir um arquétipo valorativo dotado de unidade, universalidade e indivisibilidade, sendo assim concebido no propósito de harmonicamente projetar bases seguras e satisfatórias para a coibição de tratamentos indignos à pessoa. Quadro este que se mantém em constante mutação para adequadamente cobrir todas situações desumanizadoras que demandem uma responsável e consciente cooperação jurídica, a qual deverá ser universalizada em razão do melhor atendimento à dignificação humana4.

Trata-se, portanto, da garantia de um pertinente padrão ético e normativo direcionador das condutas gerais em torno de valores tidos por basilares e universais, o qual deve ser observado e seguido por todos os Estados. Isto pois, acopla-se o ordenamento interno destes ao plano externo da ordem internacional ao fim de uma atuação, interativamente complementadora, destinada a alcançar os resultados mais favoráveis à humanidade como um todo (TRINDADE, 2002, p. 638-642). Neste sentido entende-se então que:

Os direitos humanos são, portanto, direitos protegidos pela ordem internacional (especialmente por meio de tratados multilaterais, globais ou regionais) contra as

\footnotetext{
${ }^{4}$ Para Antônio Augusto Cançado Trindade (2006, p. 07): “as sucessivas atrocidades e abusos que nas últimas décadas têm vitimado milhões de seres humanos em todas as partes têm em definitivo despertado a consciência jurídica universal (como fonte material última de todo Direito) para a premente necessidade de reconceitualizar as próprias bases do direito internacional [...]. Os avanços do ordenamento jurídico internacional correspondem à ascensão da consciência humana orientada à necessidade da realização do bem comum e da justiça”.
} 
violações e arbitrariedades que um Estado possa cometer às pessoas sujeitas à sua jurisdição. São direitos que estabelecem um nível protetivo (standard) mínimo que todos os Estados devem respeitar, sob pena de responsabilidade internacional (MAZZUOLI, 2014, p. 22).

A dignidade humana certamente há de ser tida tanto como limite quanto, simultaneamente, tarefa dos poderes estatais e de toda comunidade, mesmo porque é através da garantia de condições apropriadas ao desenvolvimento da pessoa bem como do afastamento das principais fontes de privação dos substratos que lhes são essenciais, ou seja a instituição de cenários mais dignos, que também as sociedades, porquanto caracterizadas por coletivos de indivíduos, mantêm sua higidez e alcançam melhores níveis de desenvolvimento.

É também considerada fundamento maior do classificado Direito Internacional dos Direitos Humanos5, que representa o conjunto de normas estabelecedoras de direitos e garantias atribuídos às pessoas em razão de sua própria essência humana, ao propósito do atingimento de um melhor e mais digno desenvolvimento pessoal, e opostos aos Estados para sua própria manutenção, higidez e legitimidade6. Assim pode-se afirmar que:

\begin{abstract}
$\mathrm{Na}$ busca incessante do reconhecimento, desenvolvimento e realização dos maiores objetivos por parte da pessoa humana e contra as violações que são perpetradas pelos Estados e pelos particulares, o Direito Internacional dos Direitos Humanos tem-se mostrado um instrumento vital para a uniformização, o fortalecimento e a implementação dos direitos da pessoa humana. (GUERRA, 2011, p. 131-132).
\end{abstract}

Nas vias da materialização de tais orientações é que os Estados cooperativamente produzem instrumentos internacionais, como tratados e convenções, ao propósito de formalizar deveres e responsabilidades7 a eles cabíveis na ordem jurídico-política

\footnotetext{
${ }^{5}$ Conforme bem esclarece Guilherme de Assis Almeida (2011, p. 76): “o Direito Internacional dos Direitos Humanos é um dos ramos do Direito Internacional Público; a principal novidade teórica que o primeiro traz ao campo deste último é a transformação da pessoa humana em sujeito de Direito".

${ }^{6}$ Complementa-se com os ensinamentos de Vicente Barreto (2007, p. 572) no sentido de que: "os direitos humanos, no pensamento rawlsiano, expressam-se, portanto, através de normas jurídicas e políticas, que se referem ao mundo das relações entre as nações, expressando compromissos nacionais com valores, destinados a estabelecer uma ordem internacional politicamente justa. Trata-se, em outras palavras, da remissão dos direitos humanos ao plano das relações entre os Estados que, para se legitimarem na comunidade internacional, devem ter como fundamento dos respectivos direitos internos o respeito à norma mínima internacional".

${ }^{7}$ Segundo Valerio de Oliveira Mazzuoli (2014, p. 31-32): "a responsabilidade internacional do Estado é o instituto jurídico que visa responsabilizar uma potência soberana pela prática de um ato atentatório (ilícito) ao direito internacional perpetrado contra os direitos ou a dignidade de outro Estado, prevendo certa reparação a esta último pelos prejuízos e gravames que injustamente sofreu. [...] O instituto da responsabilidade internacional tem duas principais finalidades: 1) visa coagir psicologicamente os Estados a fim de que eles não deixem de cumprir com os seus compromissos internacionais (finalidade preventiva); e 2) visa atribuir àquele Estado que sofreu um prejuízo, em decorrência de um ato ilícito cometido por outro, uma justa e devida reparação (finalidade repressiva)".
} 
internacional.8 Estes representam uma conquista expressiva principalmente porque, a partir do instante em que entram em vigência, variadas instituições, como as organizações internacionais e ONGs, em regra passam a dispor de meios mais hábeis para fazer cumprir-se a observância dos direitos elencados, tal como para suscitar a aplicação de eventuais repreensões aos violadores (ALMEIDA, 2011, p. 60).

Ora, caso não cumpridos tais compromissos pelos Estados, aos organismos internacionais competentes é atribuído o poder-dever de verificar a efetividade da aplicação dos dispositivos traçados, inclusive cabendo-lhes intentar uma possível deslegitimação ou rechaço do Estado transgressor, porquanto não cabe legitimamente reconhecer ou admitir qualquer ente sistematicamente violador dos direitos humanos9. Aliás, a negativa dos Estados em cumprir os documentos ratificados constitui razão assaz para sua responsabilização no âmbito internacional10, notadamente em se tratando de ilícitas atuações que expressam violação a esse rol de direitos vitais. Até porque:

O grau de respeito aos direitos humanos transformou-se num dos principais elementos para aferir-se a inserção de determinado país na Comunidade Internacional. [...] A política dos dirigentes, na era pós-DIDH, tem de, forçosamente, levar em conta o respeito à dignidade da pessoa humana. Resultados conseguidos à custa do desrespeito a esse valor desqualificam esses dirigentes na ordem internacional (ALMEIDA, 2011, p. 95 e p. 59).

De toda forma, em paralelo complementar, também os órgãos estatais internos devem atuar, por conta da absorção das diretrizes e valores internacionais de tutela à pessoa, com o comprometimento de verificar a observância dos direitos fundamentais bem como de assegurar as melhores e mais dignas condições de vivência e desenvolvimento humano.

Integrando as responsabilidades estatais, principalmente no viés da cooperação e solidariedade universais, se afigura imperativa uma maior preocupação e o conseguinte (re)direcionamento de esforços sobre a proteção dos refugiados. Ora, no âmbito do compartilhamento de responsabilidades, o instituto do refúgio figura justamente como um dos

\footnotetext{
${ }^{8}$ Oportunos também os dizeres cunhados por Flávia Piovesan (2010, p. 93), no sentido de que: “os instrumentos internacionais de proteção dos direitos humanos estabelecem um núcleo inderrogável de direitos, a serem respeitados seja em tempos de guerra, instabilidade, comoção pública ou calamidade pública. [...]”.

${ }^{9}$ Conforme anota Vicente Barreto (2007, p. 572): "esse conjunto de direitos tem um estatuto especial no direito interno das nações, sendo exigência básica para que um Estado possa integrar a comunidade internacional".

${ }^{10}$ Esclarecedora a explanação trazida por Francisco Rezek (2010, p. 284), no sentido de que: “a ação ou omissão caracterizada como ilícita à luz do direito das gentes deve ser imputável a uma pessoa jurídica inscrita nessa mesma ordem, ou seja, a um Estado ou a uma organização internacional. [...] Direta, por outro lado, é a responsabilidade do Estado pela ação de seus órgãos de qualquer natureza ou nível hierárquico: não está excluída a possibilidade de imputar-se ao Estado o ilícito resultante do exercício de competências legislativas ou judiciárias”.
} 
instrumentos mais significativos à possibilidade de extensão de certas responsabilidades aos integrantes da comunidade internacional.

Fenômeno este que, não obstante o trato do tema por variados instrumentos nacionais11 e internacionais, ainda não foi devidamente aportado com soluções suficientes, e assim cada vez mais irradia profundos impactos à toda extensão da comunidade internacional. Ressalva-se dessarte que "antes de mais nada, os conceitos legais, constantes da Convenção sobre Refugiados e do Protocolo, são decisivos para caracterizar as obrigações contratuais ou convencionais dos Estados que são signatários desses instrumentos" (CASELLA, 2001, p.20).

Nada obstante os progressos granjeados, é patente que ainda resta uma longa trajetória a se cumprir, mormente quanto à conscientização da sociedade global sobre a substancialidade do cumprimento dos referidos deveres contraídos pelos Estados. Isto pois, não é demais ressalvar que, na contramão de tais obrigações, infelizmente ainda são constantes e variados os episódios de desqualificação e agressões a seres humanos, além da impunidade que ainda cobre alguns agentes violadores.

A ilegitimidade das condutas infringentes exsurge justamente pela razão de que transgridem obrigações internacionais voluntariamente assumidas pelos Estados no compromisso da tutela integral da pessoa, o que torna sua condenação, além de devida e imperativa, favorável ao próprio avanço da ordem internacional no campo da tutela humana. Isto pois, fazer valer os tratados como referenciais éticos e humanísticos ajuda a corporificar o marco tão ansiado de concretização da dignidade humana, bem como se mostra também essencial à superação ou prevenção de colapsos globais. Interessante observar ademais que:

É nas grandes crises internacionais - como a atual - que se logram dar os grandes saltos qualitativos, como o ouro que se extrai da pedra bruta. $\mathrm{O}$ mundo em que vivemos muito necessita um ordenamento jurídico internacional capaz de regular eficazmente as relações entre todos os seus sujeitos (inclusive a pessoa humana), e de assim satisfazer as necessidades e aspirações da comunidade internacional, entre as quais a realização da justiça (TRINDADE, 2006, p. 26).

\footnotetext{
${ }^{11}$ No âmbito do ordenamento interno brasileiro evidencia-se a edição da Lei n. ${ }^{\circ}$ 9.474/1997 a qual, dentre outras providências, definiu mecanismos para a implementação do Estatuto dos Refugiados (da ONU) de 1951. Importante constar também que, recentemente foi editada a Lei n. ${ }^{\circ}$ 13.445/2017 a qual, se autodenominando "Lei de Migração", além de expressamente revogar a ultrapassada Lei n. ${ }^{\circ}$ 6.815/1980 ("Estatuto do Estrangeiro"), dispôs sobre direitos e deveres dos migrantes e visitantes no território nacional, bem como tratou dos denominados emigrantes. Para os fins deste, destaca-se de tal preceito (especialmente por seu artigo 121) que as disposições da Lei $n^{\circ}$ 9.474/1997 continuam aplicáveis às situações que envolvem refugiados e solicitantes, ou seja, no trato da temática dos refugiados o diploma principal e mais aplicável no Brasil continua sendo referida Lei, conjuntamente a outros específicos diplomas, nacionais e internacionais em seus campos de atuação.
} 
Mais do que proferir promissões impraticáveis e desculpas espúrias, ou procurar subterfúgios justificadores de omissões, em verdade se apresenta imperativo que sejam empenhadas ações ativas de empenho e esforço, em cooperação e reciprocidade, na diretriz da busca pela efetivação de direitos vitais para a tutela e fomento da pessoa e dignidade humana. Em raciocínio correlato, Paulo Borba Casella (2001, p. 26) tratando da problemática atinente ao enorme fluxo de refugiados infere que: "o problema é imenso; as soluções são remotas: longas filas de seres humanos, em condições as mais precárias, esperando por solução, infelizmente reclamam mais que figuras retóricas e promessas vagas".

Enfim, não obstante a paridade doutrinária e legislativa sobre a integral tutela dos direitos humanos, variadas conjunturas ainda denunciam graves violações práticas12 que acabam por vindicar a maior utilização de institutos e instituições considerados de "última ratio", do que se destaca enfocando aqui os casos de intervenção de organismos internacionais, mais especificamente quanto ao denominado Sistema Interamericano de Direitos Humanos13, bem como o fenômeno do enorme fluxo de refugiados, que refletem a drástica conjuntura hodierna de insuficiência, em alguns locais, no tratamento do ser humano, principalmente por conta da não observância dos positivados direitos humanos/fundamentais.

\section{INSTITUIÇÃO DO SISTEMA INTERAMERICANO DE PROTEÇÃO A DIREITOS HUMANOS}

Referida estrutura internacional de proteção dos direitos humanos confere posição de destaque à pessoa em todo e qualquer ordenamento, pois cunha direitos que se tornam insuscetíveis de derrogação em qualquer território, tempo ou circunstância. Inclusive, cada vez mais são empreendidas mutações em conceitos e institutos então consagrados no âmbito

\footnotetext{
${ }^{12}$ Marcante a indicação de Vicente Barreto (2007, p. 569) no sentido de que: "os direitos humanos encontram-se neste final de século em situação paradoxal: de um lado, proclamam-se em diversos textos legais um número crescente de direitos civis, políticos, sociais, econômicos e culturais, que constituem, na história do direito, a afirmação mais acabada da crença do homem na sua própria dignidade; de outro lado, esses mesmos direitos transformam-se em ideais utópicos, na medida em que são sistematicamente desrespeitados por grupos sociais e governos. Os próprios governos autoritários contribuem para a idealização dos direitos humanos, pois se preocupam mesmo em declarar a sua fidelidade a esses direitos, ainda que, cuidadosamente, defendam interpretações particulares sobre a abrangência, o sistema de proteção e a própria fundamentação dos direitos humanos".

${ }^{13}$ Interessante o estudo feito por Daniela Menengoti Gonçalves Ribeiro, Rodrigo Ichikawa Claro Silva e Maria Luiza de Souza Rocha (2017, p. 216), o qual traz em suas conclusões o seguinte excerto: "ao analisar os dados estatísticos, dentro do lapso temporal que abrange o período entre os anos de 2012 e 2016, verificou-se que a CIDH recebeu 10.486 petições, das quais cerca de $1 / 3$, mais especificamente 3.287 denúncias, foram apresentadas pelo México. Porém, no âmbito da Corte, neste mesmo período de 05 anos, foram remetidas apenas 72 denúncias, sendo sentenciadas 61 delas".
} 
do direito internacional, a exemplo da soberania dos Estados e da formação de tribunais internacionais competentes para o processo e julgamento de matérias relativas a direitos humanos (GUERRA, 2001, p. 86-89). Nesta linha, Nathália Santos Veras e Elói Martins Senhoras (2018, p. 87) evidenciam que: "hoje, prevalece o posicionamento de que a soberania deve ser exercida conforme valores éticos e democráticos".

Em paralelo ao complexo universal figuram sistemas regionais que complementam esforços no propósito do combate às violações de direitos humanos14. Consideradas suas singularidades, de serem mais específicas e adequadas, as competentes instituições dos âmbitos regionalizados revelam-se mais eficientes e positivas porque os Estados situados na mesma, ou pelo menos semelhante, conjuntura geográfica, política, econômica e cultural, denotam maior potencial a uma equilibrada transposição conjunta dos obstáculos postos (GUERRA, 2001, p. 133). Destaca-se ademais que:

\begin{abstract}
A rationale dos sistemas regionais se encontra na maior homogeneidade cultural e institucional de seus membros, que, em princípio, deveria propiciar maior efetividade a suas disposições e a seus mecanismos. A existência dessas arquiteturas regionais paralelas à arquitetura do sistema mundial, longe de enfraquecer a universalidade dos direitos humanos, visa a fortalecer sua observância com dois níveis complementares de garantias, um dos quais mais próximo às circunstâncias em que os direitos se exercem - ou devem ser exercidos (ALVES, 1997, p. 270).
\end{abstract}

Assim, para além de um pretenso garante universal de difícil realização pragmática, avigoram-se garantes locais, independentemente de suas intenções direcionadas à universalização, os quais visam assegurar certos compromissos dentro de seus territórios e competências. Observa-se que, apesar de o campo da atuação internacional, donde são realçados os esforços cooperativos gerais, tornar possível o alcance de soluções a determinados casos e pretensões mais globais, é cediço que neste quadro de atuação não se tem assegurado o mesmo nível de regularidade e exequibilidade que, geralmente, se alcança no plano estatal internalizado.

\footnotetext{
${ }^{14}$ Bem explica José Augusto Lindgren Alves (1997, p. 270) que: "à ponderável quantidade de instrumentos regulatórios e controladores dos direitos humanos construídos no âmbito das Nações Unidas agregam-se, em esforço iniciado logo após a Segunda Guerra Mundial, aqueles que compõem os sistemas regionais. Todos têm o mesmo objetivo: a integridade da pessoa humana como princípio e fim da convivência societária [...]. Alguns elementos de sistemas regionais precedem temporalmente os instrumentos internacionais da ONU, como é o caso da Declaração Americana dos Direitos e Deveres do Homem, adotada, no contexto hemisférico, oito meses antes da Declaração Universal dos Direitos Humanos, em 1948. Outros, mais do que anteceder, serviram de inspiração e impulso aos instrumentos homólogos de escopo planetário, como é o caso da Convenção Europeia para a Prevenção da Tortura e Tratamentos ou Punições Desumanos ou Degradantes com relação à Convenção da ONU contra a Tortura, de 1984, e ao protocolo a ela adicional que atualmente se negocia".
} 
Focalizando aqui, no que tange ao âmbito da local atuação institucional, o Sistema Interamericano de Direitos Humanos, cabe inicialmente assentar que este é composto pela Comissão e a Corte, competentes cada qual em suas atribuições para, trivialmente, tomar conhecimento, investigar e julgar violações de direitos humanos praticadas no âmbito dos Estados abrangidos por sua circunscrição.

Referidos órgãos diferenciam-se principalmente pela atribuição funcional, visto que apenas a Corte detém caráter jurisdicional e pode proferir sentenças, enquanto a Comissão é dotada com funções consultivas15, bem como pela capacidade de petição, pois na Comissão qualquer pessoa, grupo ou entidade, mesmo que não governamentais, desde que legalmente reconhecidos podem peticionar, enquanto na Corte apenas a Comissão e os Estados podem apresentar casos. Registra-se também que, admitido o caso, a vítima ou seu representante, bem como outras instituições, podem participar e peticionar na qualidade de amicus curiae (VERAS; SENHORAS, 2018, p. 75).

Sinteticamente é possível elencar que, para acesso a este Sistema são predicados de admissão a concreta violação de direitos, garantias e liberdades tutelados pela Convenção Americana, a legitimidade do peticionante e a descrição dos fatos (incluindo dados das vítimas, do Estado responsável e gestores encarregados, bem como a demonstração do esgotamento dos recursos de jurisdição interna ou, pelo menos, circunstâncias excessivas e injustificadas que gerem inacessibilidade ou inocuidade do âmbito estatal interno). Apesar de suas especificidades estruturais e procedimentais, ambos órgãos atuam no propósito maior da promoção, observância e defesa dos direitos humanos na circunscrição interamericana16.

A competência da Comissão alcança todos os Estados-partes signatários da Convenção Americana de Direitos Humanos (Pacto de San Jose da Costa Rica), em relação aos direitos nela positivados, além de atuar sobre os integrantes da Organização dos Estados Americanos

\footnotetext{
${ }^{15}$ Esclarece Sidney Guerra (2001, p. 183) que: "para alcançar esse desiderato, no que tange à promoção dos direitos humanos, deve a Comissão preparar estudos, relatórios e propor recomendações aos Estados, tendo em vista a adoção de medidas que favoreçam o sistema de proteção aos direitos humanos no plano doméstico, como também conhecer petições individuais e comunicações interestatais que contenham denúncias de direitos que tenham sido aviltados, nos termos da Convenção".

${ }^{16}$ Cabível a anotação feita por Daniela Menengoti Gonçalves Ribeiro, Rodrigo Ichikawa Claro Silva e Maria Luiza de Souza Rocha (2017, p. 199-200) no sentido de que: "os direitos humanos constituem eixo vital e universal de proteção da pessoa humana, abrangendo interesses individuais e, principalmente, transindividuais, numa tônica de magnitude global, tanto que, a sua tutela culminou na criação de organismos internacionais específicos. O Sistema Interamericano figura como estrutura regional de proteção e efetivação de tais direitos e tem como principal propósito o cumprimento, pelos Estados-Partes, das disposições concernentes".
} 
(“OEA”)17 em relação aos direitos consagrados na Declaração Americana dos Direitos e Deveres do Homem de 1948 e da Carta da Organização dos Estados Americanos.

Cumpre lembrar que, apesar de a competência da Comissão já ter sido adstrita à preparação de estudos, relatórios e recomendações no plano de promover a adoção de medidas protetivas dos direitos humanos, hoje também possui competência para atuar direta e efetivamente por meio do conhecimento de petições individuais e comunicações interestatais denunciantes de violações aos direitos cunhados na Convenção18. Cabe-lhe, ainda, realizar observações em determinado Estado, mediante permissão ou convite do mesmo, ao fim de avaliar a situação dos direitos humanos em dado território (GUERRA, 2001, p. 185-186).

As funções da Corte, também definidas pela Convenção Americana, ordenadamente compõem ocupações contenciosas19 e consultivas, incluindo neste segundo quadro a emissão de pareceres sobre a compatibilidade entre leis internas de determinado Estado e os instrumentos internacionais indicados como parâmetro20. No âmbito da competência contenciosa cabe inclusive a execução de medidas punitivas ao fim de que seja assegurado às vítimas a devida reparação21, bem como responsabilizados, na ordem da atuação do tribunal internacional competente, os agentes violadores das normas de proteção humana22.

\footnotetext{
${ }^{17} \mathrm{O}$ artigo 106 da Carta da Organização dos Estados Americanos (“Carta da OEA") inclusive prevê o seguinte: "Haverá uma Comissão Interamericana de Direitos Humanos que terá por principal função promover o respeito e a defesa dos direitos humanos e servir como órgão consultivo da Organização em tal matéria. Uma convenção interamericana sobre direitos humanos estabelecerá a estrutura, a competência e as normas de funcionamento da referida Comissão, bem como as dos outros órgãos encarregados de tal matéria.

${ }^{18}$ Oportuno constar a anotação de José Augusto Lindgren Alves (1997, p. 280) no sentido de que: "a CIDH, conforme anteriormente assinalado, é entidade que preexistia à Convenção Americana dos Direitos Humanos, cuja competência e status dentro da OEA foram gradativamente incrementados. De instituição meramente "promotora" dos direitos humanos, função de que se desempenhava por meio de atividades de divulgação dos direitos humanos definidos na Declaração continental, alcançou ela a categoria de órgão permanente da OEA pelo Protocolo de Buenos Aires de 1967 - vigente desde 1970. Com a Convenção Americana dos Direitos Humanos a CIDH passa a ser também órgão de implementação desse instrumento jurídico. E tem suas funções fortalecidas ainda mais, atingindo níveis quase judiciais".

${ }^{19}$ Observa Sidney Guerra (2001, p. 189) que: "a competência contenciosa será ratione personae, ratione materiae e ratione temporis".

${ }^{20}$ Trata-se do denominado controle de convencionalidade, o qual pode ser exercido pelo próprio Estado por meio de seus órgãos internos, ou por outros Estados e organizações que componham a comunidade internacional, em determinado contexto, inclusive para fins de responsabilização do Estado.

${ }^{21}$ Esclarece José Augusto Lindgren Alves (1997, p. 284) que: "a Corte Interamericana de Direitos Humanos é instância judicial, mas suas sentenças não são punitivas. Procuram assegurar ação corretiva para as deficiências dos sistemas judiciários nacionais. A correção tem sido igualmente determinada na forma de indenização pelo Estado às vítimas ou seus familiares".

${ }^{22}$ Conforme esclarece Sidney Guerra (2001, p. 189): "a Corte deve exercer sua competência contenciosa considerando a responsabilidade do Estado pela violação, uma vez que este se obrigou, ao retificar a Convenção Americana sobre Direitos Humanos, a não só garantir como prevenir e investigar, usando todos os recursos que dispuser para impedir as violações da Convenção Americana. Desses compromissos derivam obrigações de punir, com o rigor de suas normas internas, os infratores de normas de direitos humanos constantes de sua legislação e da Convenção Americana, assegurando à vítima a reparação adequada".
} 
Diante a instituição deste quadro de atribuições, a busca pela maior efetividade dos direitos humanos teve reforçada sua posição de destaque na ordem americana, notadamente porque a violação a tal arcabouço protetivo legitima o acionamento dos órgãos que atuam na instância supranacional23, a qual transcende as restritivas circunscrições assumidas pelas Cortes estatais e chancela a atuação direta e efetiva destes. Necessário ressalvar ademais que:

\begin{abstract}
Seria incorreto visualizar os órgãos convencionais internacionais de proteção dos direitos humanos como instâncias de revisão, por exemplo, de decisões de tribunais nacionais; disto não se trata. No entanto, tais órgãos internacionais podem, e devem, no contexto de casos concretos de violações de direitos humanos, determinar a compatibilidade ou não com os respectivos tratados de direitos humanos, de qualquer ato ou omissão por parte de qualquer poder ou órgão ou agente do Estado inclusive leis nacionais e sentenças de tribunais nacionais. Trata-se de um princípio básico do direito da responsabilidade internacional do Estado, aplicado no presente domínio de proteção dos direitos humanos (TRINDADE, 2002, p. 693).
\end{abstract}

Assim, figurando como estrutura regional de proteção à pessoa, o Sistema Interamericano compõe um pilar importante no combate a circunstâncias configuradoras de cenários de sistemática violação aos direitos humanos24, principalmente porque, conforme dito, legitima a atuação de órgãos que, transcendendo os limites da soberania estatal, com a chancela internacional responsabilizam os entes nacionais por conta de suas ações e omissões contrárias à ordem de uma maior e mais indistinta proteção fomentadora da pessoa25.

\footnotetext{
${ }^{23}$ Interessante o estudo feito por Daniela Menengoti Gonçalves Ribeiro, Rodrigo Ichikawa Claro Silva e Maria Luiza de Souza Rocha (2017, p. 215), o qual assentou a seguinte conclusão: "assim, conforme análise referente aos casos e períodos delineados, infere-se que a média temporal de espera dos casos na Comissão, até a rejeição ou o oferecimento da denúncia à Corte, é aproximadamente de 12 anos. Quanto ao tempo de espera para proclamação de sentença pela Corte tem-se uma média de 02 anos. [...]. Tratando-se do aspecto referente aos direitos humanos, tem-se que, nos 61 casos observados, os direitos que mais constam em petições como tendo sido violados foram: Garantias Judiciais (citado em 54 casos), Integridade Pessoal (43 casos), Proteção Judicial (42 casos), Liberdade Pessoal (28 casos), e o Direito à Vida (27 casos). Os demais constaram na seguinte ordem: Propriedade Privada (14), Circulação e Residência (11), Reconhecimento da Personalidade Jurídica (11), Proteção à Família (10), Pensamento/Expressão (8), Honra e Dignidade (6), Igualdade Perante a Lei (5), Legalidade/Retroatividade (5), Direitos Políticos (4), Liberdade de Associação (4), Proibição à Escravidão e Servidão (1), Direito de Reunião (1), Nacionalidade (1), e, Nome (1). [..]. Os países que mais encaminharam petições à Comissão nos referidos anos, conforme demonstrado, são o México, com cerca de 3287 petições, e a Colômbia, com aproximadamente 2041 petições".

${ }^{24}$ Exemplifica Sidney Guerra (2001, p. 193) que: “de fato, o papel da Corte Interamericana de Direitos Humanos é bastante relevante no contexto regional principalmente se levarmos em consideração as barbaridades que foram praticadas no continente, especialmente no período recente de golpes militares que corresponderam a verdadeiros abusos e denegação de direitos".

${ }^{25}$ Lembra Antônio Augusto Cançado Trindade (2006, p. 28) que: "ninguém poderia supor ou prever, há alguns anos atrás, que as causas dos deslocados, dos marginalizados e excluídos, dos migrantes indocumentados (em busca de alimento, moradia, trabalho e educação), e das crianças abandonadas nas ruas, alcançassem um tribunal internacional como a Corte Interamericana de Direitos Humanos, como tem efetivamente ocorrido, de modo sistemático, a partir de sua Sentença de 1999 no caso paradigmático dos "Meninos de Rua" (Villagrán Morales e Outros). O fato de ter-se tornado o acesso dos pobres e oprimidos à justiça internacional uma realidade em nossos dias se deve, sobretudo, em meu entender, ao despertar da consciência humana para as necessidades de proteção dos mais fracos e dos esquecidos".
} 


\title{
4 O INSTITUTO DO REFÚGIO EM RAZÃO DAS VIOLAÇÕES AOS DIREITOS HUMANOS
}

O fenômeno do refúgio ainda se afigura crônico e persistente porque a humanidade queda-se incompetente em extirpar os graves problemas que afligem determinadas pessoas as quais chegam ao ponto de restar obrigadas a buscar outros territórios, que não aqueles onde vinham mantendo suas raízes, por necessidade de sobrevivência.

No refúgio, a pessoa deixa seu país por sofrer ou estar na iminência da violação de direitos vitais, visando assim integrar a ordem jurídica de outro país, no qual pretende ter garantida a proteção que lhe cabe não apenas por conta do reconhecimento de sua condição como migrante26 refugiado, mas pela própria essência de ser humano que lhe dota, ao menos em tese, de uma dignidade fomentadora da melhor proteção jurídico-político-social27. Sobre o âmbito da atuação institucional prática observa-se que:

\begin{abstract}
Nessa operação atua como terceiro um órgão da $\mathrm{ONU}$, diretamente ligado à Assembleia Geral: O Alto Comissariado das Nações Unidas para os Refugiados (Acnur), supervisionando e controlando a aplicação do Direito Internacional dos Refugiados (DIR), bem como protegendo os direitos humanos dos buscadores de asilo e refugiados quando, por ventura, eles sejam violados pelo país perseguidor ou pelo país de asilo (ALMEIDA, 2011, p. 98).
\end{abstract}

Genericamente as pessoas abarcadas por tais institutos são aquelas que, por não se sujeitarem à ordem que violentamente impera em suas terras, donde na maioria das vezes são configurados trágicos cenários de guerra28, intolerância, perseguição e miséria, acabam despidos de outras opções que não a de fugir para buscar acolhimento noutro lugar, em que a

\footnotetext{
${ }^{26}$ Lembram Nathália Santos Veras e Elói Martins Senhoras (2018, p. 79) também que: “a preocupação com os direitos e deveres relacionados à migração levou a OEA a instituir o Programa Interamericano para a Promoção e Proteção dos Direitos Humanos dos Migrantes, incluindo os Trabalhadores Migrantes e suas Famílias. Apesar disso, atualmente, os direitos desse grupo são pouco normatizados regionalmente. $\mathrm{O}$ que existe é a Convenção Interamericana contra Toda Forma de Discriminação e Intolerância, cujo texto faz menção especial aos migrantes, e a Declaração de Cartagena, que trata dos refugiados".

${ }^{27}$ Mais especificamente ao internacional trato jurídico dos refugiados, Paulo Borba Cassela (2001, p. 21) anota que: "em se tratando de Estados não signatários da Convenção ou do Protocolo, ou outra convenção com objetivo semelhante, é preciso buscar amparo no Estatuto do Alto Comissariado das Nações Unidas para Refugiados, e outras resoluções da Assembleia Geral da ONU ou mesmo de outros organismos internacionais. O mesmo se aplica, até certo ponto, com relação a Estados que ratificaram a Convenção, com restrições geográficas - com clausulas tais como "refugiados resultantes de eventos ocorridos na Europa" - ou Estados que não sejam signatários do Protocolo de 1967, ou assuntos não regulados pela Convenção. Nestes casos, será preciso procurar soluções em outras regras de direito internacional".

${ }^{28}$ Exemplificativamente, lembra-se com Valerio de Oliveira Mazzuoli (2014, p.265) que: "o tema dos refugiados tem ganhado a atenção especial do direito internacional a partir da década de 1920, em decorrência dos acontecimentos do pós-Primeira Guerra, intensificando-se a partir da Segunda Guerra Mundial. Trata-se de uma das primeiras preocupações do direito do pós-guerra a inspirar toda uma legislação protetiva após esse período".
} 
sua situação é também incerta. De toda forma, independentemente da causa, o enredo do refúgio representa um trágico corolário do quadro de ofensas à pessoa. Aliás, não somente as causas, mas as consequências são também, e ainda mais, desumanizadoras.

Independentemente dos quadros característicos que lhes envolvam, estes indivíduos representam a intolerância e despudor daqueles que se pretendem "senhores da humanidade" e portadores das verdades (culturais, religiosas, políticas etc.). Decorrência esta que projeta o sectarismo e a exclusão de milhões de pessoas ao redor do mundo por conta de cruéis atitudes que, baseadas em determinado projeto ou dogma discriminador, fazem vítimas de toda ordem e desumanizam o próprio ser, a ponto de mesmo os opressores, já repugnantes por suas próprias condutas hediondas, obstinarem a degenerar-se eles mesmos (BOFF, 1997, p. 5).

Os solicitantes de refúgio e de asilo29 refletem o insucesso no alcance de uma proteção integral, ou ao menos satisfatória, dos direitos humanos, o que culmina na configuração de indivíduos profundamente afetados e vulneráveis à discriminação e opressão de outrem, visto que figuram desnudados das condições mais básicas à autodeterminação pessoal e desenvolvimento livre da sua personalidade de forma digna. Simbolizam assim a significativa representação de uma figura antagônica aos propósitos da instituição dos direitos humanos. Indubitável ademais que:

Cada refugiado é consequência de um Estado que viola os direitos humanos. Todos os refugiados têm sua própria história - uma história de repressão e abusos, de temor e medo. Há que se ver em cada um dos homens, mulheres e crianças que buscam refúgio o fracasso da proteção dos direitos humanos em algum lugar (PIOVESAN, 2001, p. 38).

E tendo em vista que revela-se ainda crescente a já colossal quantidade de indivíduos que, vilipendiados em seus direitos mais vitais e tendo suas personalidades ignoradas, apresentam-se a outro Estado em busca de um mínimo de reconhecimento, pelo menos quanto à sua própria identidade ou condição de ser humano, é possível inferir que, infelizmente, não

\footnotetext{
${ }^{29}$ Conforme os ensinamentos de Flavia Piovesan (2001, p. 57-59), podem ser tecidas algumas diferenças entre asilo e refúgio. Assim, vislumbra-se inicialmente que o refúgio é um instituto jurídico internacional, tendo alcance universal, e o asilo é um instituto jurídico regional, tendo alcance na região da América Latina. O refúgio é medida essencialmente humanitária, enquanto o asilo é medida essencialmente política. O refúgio abarca motivos religiosos, raciais, de nacionalidade, de grupo social e de opiniões políticas, enquanto o asilo se concentra em ações de natureza política. Para o refúgio basta um fundado temor de perseguição, enquanto para o asilo há necessidade de ser efetivada a perseguição. No refúgio a proteção, como regra, se opera fora do país, já no asilo a proteção pode se dar no próprio país ou na embaixada do país de destino (asilo diplomático). No refúgio há cláusulas de cessação, perda e exclusão, constantes da Convenção sobre o Estatuto dos Refugiados, já no asilo inexistem tais cláusulas. Enquanto a concessão de refúgio apresenta efeito declaratório, a concessão de asilo apresenta efeito constitutivo, dependendo exclusivamente da decisão do país. De toda forma, tais institutos se identificam por constituírem medida unilateral destituída de reciprocidade e, sobretudo, por objetivarem fundamentalmente a proteção humana, daí sua necessária harmonização e complementaridade.
} 
obstante os esforços cooperativos e a ampla legislação globalizada, os direitos humanos estão, diuturnamente, sendo agredidos.

Desta decorrência eclodem enormes desafios e obstáculos os quais estorvam a realização e formação tanto da pessoa que, além de restar desarraigada de sua pátria e laços sociais ou familiares, figura numa situação de desamparo e vulnerabilidade causada pelas violações e incertezas que lhes atingem derruindo sua própria integridade (física ou psicológica), quanto da própria estrutura social ou estatal que, em verdade, apenas há de existir e se manter enquanto represente a devida reunião de múltiplos indivíduos que com ela estejam satisfeitos ou, pelo menos, por ela amparados. Tomadas as proporções atuais, tanto da extensão de seu atingimento quanto da gravidade de suas consequências, pode-se inferir que:

\begin{abstract}
A melhor maneira de definir a questão dos refugiados em apenas uma frase poderia ser "The burden o four time" [O fardo de nossa época]. Este o título da primeira edição inglesa de "Origens do Totalitarismo", obra em que Hannah Arendt, ao desenvolver seu pensamento sobre imperialismo, intui ser a questão dos refugiados a grande questão desse século, quando cuida das displaced persons [pessoas deslocadas] (ARAÚJO; ALMEIDA, 2001, p. 1).
\end{abstract}

Sobrevém, então, uma premente necessidade quanto ao melhor trato desta conjuntura, notadamente sobre a adoção de medidas mais palpáveis e completas que, realmente, concretizem o espírito da ordem normativa. É preciso observar ainda que, não se trata apenas da busca pela tão desejada diminuição do fluxo de refugiados, mas também sobre a maior atenção e suporte devidos aos já refugiados, pois em sua grande maioria ainda vivem sob precárias e cruéis condições.

Além do mais, clama-se principalmente pela efetivação de ações mais incisivas ao saneamento dos perversos contextos que ainda se mantêm em determinados países "produtores de refugiados", ou seja, o empenho de um enérgico combate às circunstâncias violadoras de direitos humanos nos países de origem, sistematicamente causadores desta intensificação dos quadros do refúgio. Disto infere-se sobretudo que "zelar pelo respeito aos direitos humanos, em qualquer parte do planeta, é, portanto, prevenir a ocorrência de acontecimentos históricos geradores de refugiados" (ALMEIDA, 2011, p. 107).

É propriamente deste deslinde, ademais, que aflora com maior força a imperatividade de um trato mais solidário no que tange à ação de acolhida, independentemente dos vínculos formais delineados em cada Estado, ou seja, o melhor recebimento dos indivíduos independentemente de sua nacionalidade, pois trata-se de pessoas que, exclusivamente por 
isso, já fazem jus à melhor proteção que lhes possa ser direcionada em prol da tutela e fomento da dignidade humana.

De toda forma, referida solidariedade deve ser eficiente e verdadeira o bastante para efetivamente modificar realidades, em especial quanto ao propósito de firmar que os Estados cumpram suas obrigações morais, jurídicas e políticas em condições coerentes de fraternidade e honradez, dentro de um institucionalizado patamar em que significativos entes mundiais assumam, com propósitos humanos e não meramente comerciais, as frentes de resolução dos complexos problemas que flagelam a humanidade Perspicaz a exemplificativa apuração de Alain Supiot (2007, p. 268) no sentido de que:

\begin{abstract}
Abertas às coisas, essas fronteiras permanecem fechadas aos homens, e não existe livre circulação das pessoas em escala internacional. Depois de ter celebrado ontem como heróis os dissidentes que conseguiam fugir dos países comunistas, os países ocidentais escorraçam hoje os 'sem-documentos' que procuram fugir dos países do Sul. E evitam discorrer sobre as razões dessa fuga, pois isso os obrigaria a encarar de frente os efeitos devastadores do regime das trocas que eles impõem ao mundo. A Organização Mundial do Comércio (OMC) fez saber claramente que, afora as questões muito pontuais visadas por seus estatutos, o destino dos homens não era de sua alçada.
\end{abstract}

Seguindo esta linha, e diante a insuficiência dos modelos tradicionalmente adotados, os quais demandam, no mínimo, flexibilizações para sua melhor adequação à realidade social, os próprios fundamentos da soberania e da vinculação indivíduo-Estado por meio da nacionalidade, por exemplo, precisam em certa forma ser (re)formulados no propósito de alcançar um maior grau de reconhecimento, amparo e integração dos indivíduos a sociedades efetivamente garantidoras de sua proteção integral30. Isto porque certos conceitos enraizados não mais se mostram capazes de suficientemente manter sua legitimidade porquanto ainda propiciam a ocorrência de vastos desarrimos massificados.

Nada obstante, por óbvio, não se pode desprezar os benefícios consolidados e avanços alcançados com os modelos e ordenamentos então adotados, principalmente no âmbito da proteção dos direitos humanos, ao passo que os projetos a serem agora realizados devem

\footnotetext{
${ }^{30}$ Conforme bem salienta Giorgio Agamben (2007, p. 138-141).: "o refugiado deve ser considerado por aquilo que é, ou seja, nada menos que um conceito-limite que põe em crise radical as categorias fundamentais do Estado-nação, do nexo nascimento-nação aquele homem-cidadão, e permite assim desobstruir o campo para uma renovação categorial atualmente inadiável, em vista de uma política em que a vida nua não seja mais separada e excepcionada no ordenamento estatal, nem mesmo através da figura dos direitos humanos [...] Se os refugiados (cujo número nunca parou de crescer no nosso século [século XX], até incluir hoje uma porção não desprezível da humanidade) representam, no ordenamento do Estado-nação moderno, um elemento tão inquietante, e antes de tudo porque, rompendo a continuidade entre homem e cidadão, entre nascimento e nacionalidade, eles põem em crise a ficção originária da soberania moderna".
} 


\section{PARA ALÉM DA FRONTEIRA NACIONAL: A NECESSIDADE DE MECANISMOS PARA ABRANDAMENTO DOS REFLEXOS INTERNACIONAIS DAS VIOLAÇÕES DE DIREITOS

acrescer, na maior medida possível, esforços práticos31 que possam paulatinamente contribuir à reversão dos efeitos negativos que ainda assolam o presente quadro social já tão afetado32, principalmente porque representam passos significativos à direção do equilíbrio e desenvolvimento tão almejados pelas formações sociais. Observa-se ademais que:

O nexo entre asilo, refugiados e paz não deve ser subestimado. Ao garantir um acesso justo aos procedimentos de asilo, ao garantir uma vida digna e o acesso aos direitos básicos à pessoa, estamos, todos, colocando nosso grão de areia para a construção da paz e segurança regionais (PITA, 2016, p. 16).

Não se tratando de casos isolados, mas de um constante fluxo massificado que reflete a séria incapacidade de o mundo atual solucionar tal problemática, ou ao menos conferi-la um concreto trato adequado e suficiente, resta cediço que o arcabouço protetivo dos direitos humanos não vem sendo satisfatoriamente cumprido. Não parece demais afirmar ainda que, é justamente sobre a extrema situação de desamparo e desesperança que paira sobre os refugiados que se observa a mais agoniante suplica pela atuação de terceiros, o que enseja uma típica ação de solidariedade e compartilhamento de responsabilidades.

\section{CONSIDERAÇÕES FINAIS}

É irrepreensível que o ordenamento global possa se servir de um hábil conjunto de medidas e instrumentos, mais amplo e completo do que o presente em outras épocas, para extirpar quaisquer normas e condutas violadoras das tratativas internacionais de proteção aos direitos humanos. Mas na prática decorre que, não obstante referido arcabouço protetivo,

\footnotetext{
${ }^{31}$ Como exemplo, a seguinte constatação feita por Flavia Piovesan (2001, p. 43): "em virtude da complexidade da crise global de refugiados, a Conferência Mundial sobre Direitos Humanos reconhece, de acordo com a Carta das Nações Unidas, com os instrumentos internacionais que se referem à matéria, em sintonia com o espirito de solidariedade internacional e com a necessidade de compartilhar responsabilidades (burden-sharing), que a comunidade internacional deve adotar um planejamento abrangente em seus esforços para coordenar as atividades e promover uma maior cooperação com países envolvidos e com organizações pertinentes a essa área, tendo em mente o mandato do ACNUR. Esse planejamento deve incluir: o desenvolvimento de estratégias que abordem as causas mais profundas e os efeitos dos movimentos de refugiados e de outras pessoas deslocadas; o fortalecimento de medidas preparatórias e mecanismos de resposta a emergências; o estabelecimento de uma efetiva proteção e assistência, levando-se em conta de modo especial as necessidades de mulheres e crianças; a busca permanente de soluções duradouras, preferencialmente a repatriação voluntaria de refugiados em condições de segurança e dignidade, bem como outras soluções que têm sido adotadas pelas conferencias internacionais sobre refugiados. A Conferência Mundial sobre Direitos Humanos enfatiza a responsabilidade dos Estados quanto à problemática dos refugiados, particularmente no que concerne ao país de origem".

${ }^{32}$ Conforme bem ilustra Paulo Borba Casella (2001, p. 26): "o problema é imenso; as soluções são remotas: longas filas de seres humanos, em condições as mais precárias, esperando por solução, infelizmente reclamam mais que figuras retóricas e promessas vagas".
} 
ainda são correntes trágicas e preocupantes condutas que, em total revelia aos apelos e fundamentos da comunidade internacional, implementam vilipêndios à tutela humana.

Deste cenário é que exsurgiu a maior atuação da ordem internacional por meio de certos órgãos, institutos e instituições, do que pontuado neste trabalho a competência do Sistema Interamericana de Direitos Humanos e o fenômeno do refúgio. Isto pois, cada vez mais é suscitada a cooperação dos Estados quanto ao amparo de indivíduos que, tendo seus direitos humanos violados ou ameaçados no país de origem, não veem outra esperança senão fugir ou confiar sua tutela a órgãos externos.

Ou seja, em razão da ainda constante violação de direitos humanos e afronta à dignidade humana, apesar de todo o arcabouço teórico-normativo de proteção, alguns instrumentos e mecanismos (como a atuação de organismos internacionais e a criação de institutos como o refúgio e o asilo) ainda se mostram demasiadamente necessários para o abrandamento dos constantes reflexos negativos de tais conjunturas, enquanto insuficientes os esforços empenhados à cessação das causas dessas afrontas.

De toda forma há que se inferir também, pelo próprio âmago do sistema protetivo hodierno, que pouca ou nenhuma justificativa ou conjuntura pode ser bastante para conseguir legitimar a irresponsabilidade ou impunidade estatal quando este viola direitos globalmente consagrados, sobretudo na medida em que estes se apresentem inerentes à própria natureza humana. Ademais, é justamente por conta das obrigações, gerais ou específicas, assumidas pelos Estados perante a ordem internacional que têm estes o dever, diplomático ou impositivo, de empregar todas as técnicas e providências necessárias à integral tutela humana.

Figurando então qualquer indivíduo em cenário de violação a direitos humanos deve ser realizada a maior movimentação, tanto do Estado quanto da comunidade internacional, em prol da garantia de condições suficientes ao pleno e livre desenvolvimento da pessoa, sob pena de se desprezar a própria qualidade humana. Isto deve, ademais, independer do Estado de origem ou de reservas feitas pelos Estados de acolhida, pois a soberania estatal não pode ser tida por tão absoluta ou inflexível a ponto de tornar impossível a efetiva solução perene.

Aliás, já pela própria unidade cooperativa que deve pairar sobre a ordem internacional em prol da tutela humana, se apresenta totalmente cabível e acertada a intervenção de órgãos externos no propósito de responsabilização dos agentes descumpridores dos deveres assumidos. Isto pois, devem todos os Estados figurar numa posição de cooperação solidária direcionada à erradicação das desumanas condições que ainda afetam milhões de pessoas. 
Para além de meros paliativos, a situação deve ser tratada com instrumentos efetivos no alcance de soluções permanentes e universalizadas em um labor cooperativo que, em verdade, há de se concentrar na erradicação das principais fontes de infringência aos direitos humanos. Isto pois, apesar da grande importância destes institutos, a resposta não está no refúgio ou julgamento pela Corte Interamericana, que são medidas de abrandamento das drásticas consequências à pessoa, mas sim no combate das causas em âmbito de prevenção.

Além do mais, apresenta-se totalmente desejável o fato de se poder assegurar em todos os espaços geográficos do globo terrestre, independentemente dos traços soberanos ou da forma adotada pelos Estados, que toda pessoa possa se expressar, de forma livre e suficiente, nos campos político, jurídico, social, econômico, religioso ou outros, por suas próprias opiniões e ideologias, num cenário de respeito e consideração mútuos, sem qualquer tipo de tortura, ameaça ou outro tipo de intolerância, bem como possa transitar livremente sem medo. Aliás, parecem ser estes os traços mínimos da efetiva humanização da sociedade.

Tudo em prol da dignidade humana que, em razão da essencialidade de seu amparo, apresenta-se na posição de principal premissa e diretriz norteadora de qualquer ordenamento jurídico-político-social, que nela se há de pautar e a ela destinar o centro do destaque de suas agendas e ações, com todos seus esforços, sob pena de a própria humanidade ser atingida em sua higidez, desenvolvimento e legitimidade.

\section{REFERÊNCIAS}

AGAMBEN, Giorgio. Homo sacer o poder soberano e a vida nua. Belo Horizonte- MG: UFMG, 2007.

ALMEIDA, Guilherme Assis de. Direitos humanos e não-violência. São Paulo: Atlas, 2011.

ALVES, José Augusto Lindgren. A arquitetura internacional dos direitos humanos. São Paulo: FTD, 1997.

ARAÚJO, Nadia de; ALMEIDA, Guilherme de Assis (Coord.) O direito internacional dos refugiados: perspectiva brasileira. Rio de Janeiro: Renovar, 2001.

BARRETO, Vicente. Ética e Direitos Humanos: Aporias Preliminares. In: TORRES, Ricardo Lobo. Legitimação dos Direitos Humanos. Rio de Janeiro: Renovar, 2007.

BOFF, Leonardo. A águia e a galinha, a metáfora da condição humana. 40. ed. Petrópolis, RJ: Vozes, 1997. 
BRASIL. Constituição Federal de 1988. Diário Oficial [da] República Federativa do Brasil. Disponível em: <http://www.planalto.gov.br/ccivil_03/constituicao/constituicaocompilado.htm>. Acesso em: 23 jun. 2018.

CASELLA, Paulo Borba. Refugiados: conceito e extensão. In: ARAÚJO, Nadia de; ALMEIDA, Guilherme de Assis (Coord.) O direito internacional dos refugiados: perspectiva brasileira. Rio de Janeiro: Renovar, 2001.

CIDH. Comissão Interamericana de Direitos Humanos. Declaração americana dos direitos e deveres do homem. 1948.2 Disponível em: <https://www.cidh.oas.org/basicos/portugues/b.Declaracao_Americana.htm>. Acesso em: 25 ago. 2018.

GUERRA, Sidney. Direito internacional dos direitos humanos. São Paulo: Saraiva, 2011.

HABERLE, Peter. A dignidade humana como fundamento da comunidade estatal. In: SARLET, Ingo Wolfgang. Dimensões da dignidade: ensaios de filosofia do direito e direito constitucional. Porto Alegre-RS: Livraria do Advogado, 2013.

MAZZUOLI, Valério de Oliveira. Curso de direitos humanos. São Paulo: Método, 2014.

OEA. Organização dos Estados Americanos. Carta da Organização dos Estados Americanos (A-41). Disponível em: <https://www.oas.org/dil/port/tratados_A41_Carta_da_Organização_dos_Estados_Americanos.pdf>. Acesso em: 22 mar. 2018.

ONU. Organização das Nações Unidas. Convenção Americana sobre Direitos Humanos. 22 de novembro de 1969.1 Disponível em: <https://www.cidh.oas.org/basicos/portugues/c.convencao_americana.htm>. Acesso em: 22 mar. 2018.

PIOVESAN, Flavia. Direito internacional dos direitos humanos e lei de anistia: o caso brasileiro. In: IKAWA, Daniela; PIOVESAN, Flavia; FACHIN, Melina Giardi (org). Direitos humanos na ordem contemporânea: proteção nacional, regional e global. Curitiba: Juruá, 2010.

O direito de asilo e a proteção internacional dos refugiados. In: ARAÚJO, Nadia de; ALMEIDA, Guilherme de Assis (Coord.) O direito internacional dos refugiados: perspectiva brasileira. Rio de Janeiro: Renovas, 2001.

PITA, Agni Castro. À guisa de prefácio. Direitos humanos e direito internacional dos refugiados. In: GEDIEL, José Antônio Peres; GODOY, Gabriel Gualano de (Org.). Refúgio e hospitalidade. Kairós, 2016.

REZEK, Francisco. Direito internacional público: curso elementar. 12. ed. São Paulo: Saraiva, 2010.

RIBEIRO, Daniela Menengoti Gonçalves; ROCHA, Maria Luiza de Souza; SILVA, Rodrigo Ichikawa Claro. A efetividade do acesso à justiça no sistema interamericano de direitos 
humanos: uma análise das decisões da corte interamericana proferidas no período de 2012 a 2016. In: RIBEIRO, Daniela Menengoti Gonçalves; ÁVILA, Gustavo Noronha de; MEZACASA, Douglas Santos (Org.) Efetividade dos direitos fundamentais. Rio de Janeiro: Lumen Júris, 2017.

SARLET, Ingo Wolfgang. As dimensões da dignidade da pessoa humana: construindo uma compreensão jurídico-constitucional necessária e possível. In: SARLET, Ingo Wolfgang. Dimensões da dignidade: ensaios de filosofia do direito e direito constitucional. Porto AlegreRS: Livraria do Advogado, 2013.

SUPIOT, Alain. Homo juridicus: ensaio sobre a função antropológica do direito. São Paulo: WMF Martins Fontes, 2007.

TRINDADE. Antônio Augusto Cançado. O direito internacional em um mundo em transformação. Rio De Janeiro: Renovar, 2002.

. A humanização do direito internacional. Belo Horizonte: Del Rey LTDA, 2006.

VERAS, Nathália Santos; SENHORAS, Elói Martins. Direito dos migrantes e a corte interamericana de direitos humanos. Boa vista: editora UFPR, 2018. 